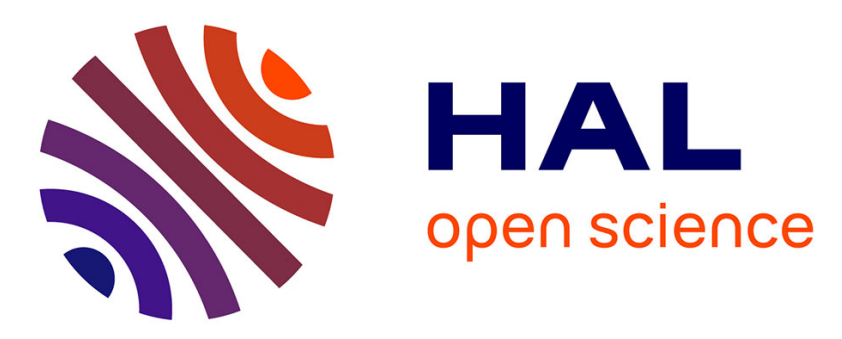

\title{
Ge doped GaN and Al 0.5 Ga 0.5 N-based tunnel junctions on top of visible and UV light emitting diodes
}

\author{
V. Fan Arcara, B. Damilano, G. Feuillet, S. Vezian, K. Ayadi, S. Chenot, \\ J.-Y. Duboz
}

\section{- To cite this version:}

V. Fan Arcara, B. Damilano, G. Feuillet, S. Vezian, K. Ayadi, et al.. Ge doped GaN and Al 0.5 Ga 0.5 N-based tunnel junctions on top of visible and UV light emitting diodes. Journal of Applied Physics, 2019, 126 (22), pp.224503. 10.1063/1.5121379 . hal-02569339

\section{HAL Id: hal-02569339 \\ https://hal.science/hal-02569339}

Submitted on 25 Nov 2020

HAL is a multi-disciplinary open access archive for the deposit and dissemination of scientific research documents, whether they are published or not. The documents may come from teaching and research institutions in France or abroad, or from public or private research centers.
L'archive ouverte pluridisciplinaire HAL, est destinée au dépôt et à la diffusion de documents scientifiques de niveau recherche, publiés ou non, émanant des établissements d'enseignement et de recherche français ou étrangers, des laboratoires publics ou privés. 


\title{
Ge doped $\mathrm{GaN}$ and $\mathrm{Al}_{0.5} \mathrm{Ga}_{0.5} \mathrm{~N}$-based tunnel junctions on top of visible and $\mathrm{UV}$ light emitting diodes
}

\author{
V. Fan Arcara ${ }^{1,2, a)}$, B. Damilano ${ }^{1}$, G. Feuillet ${ }^{2}$, S. Vézian ${ }^{1}$, K. Ayadi ${ }^{1}$, S. Chenot $^{1}$, J-Y. Duboz $^{1}$ \\ 1 : CNRS, Université Côte d'Azur, CRHEA, Rue Bernard Grégory, 06560 Valbonne, France \\ 2: CEA - LETI, MINATEC Campus, 17 Rue des Martyrs, 38054 Grenoble, France \\ a) Corresponding author. Email:vfa@crhea.cnrs.fr, Phone: +33493954217
}

\begin{abstract}
$\underline{\text { Abstract }}$
The use of tunnel junctions (TJs) is a potential solution in blue LEDs to poor p-contacts, replacing it by another n-contact. TJs are even more advantageous for UV emitting structures, which suffer from the considerably low injection efficiency in high Al concentration UV LEDs. In this work we report our work on Ge n-doped GaN and AlGaN TJs grown on top of blue and UV LEDs, respectively, by a hybrid growth. We have achieved state of the art mobility $\left(67 \mathrm{~cm}^{2} / \mathrm{V} . \mathrm{s}\right)$ and resistivity $\left(1.7 \times 10^{-4} \Omega . \mathrm{cm}\right)$ at a free electron concentration of $5.5 \times 10^{20} \mathrm{~cm}^{-3}$ in Ge-doped GaN. With an emission wavelength of $436 \mathrm{~nm}$, the GaN TJ slightly increased the optical power of the blue LED. The AlGaN TJs, on the other hand, improved the optical power of the UV LED $(304 \mathrm{~nm})$ by at least a factor of 3 , suggesting the enhancement of the hole injection efficiency by the use of TJs in UV emitting structures.
\end{abstract}

\section{$\underline{\text { Introduction }}$}

The increasing demand for ultraviolet (UV) sources has motivated the recent advances in the required materials and their synthesis. By introducing $\mathrm{Al}$ in the $\mathrm{GaN}$ lattice, one can decrease the wavelength of emission from blue or near-UV emission down to the UV-C range as the $\mathrm{Al}$ concentration, and consequently the bandgap, increases. However, the wall plug efficiency (WPE) of the UV-LED decreases due to the deepening of Mg-acceptors (necessary for p-doping) as the band gap increases, ${ }^{1,2}$ correlatively to the increase of the access resistance on the $\mathrm{p}$-side of the LED. 
This issue can be addressed by the deposition of a p-GaN layer on top of the LED, due to the shallower Mg acceptors when compared to those in $\mathrm{p}-\mathrm{AlGaN}$. This is in use in most commercial UV LEDs at present, but it limits the light extraction efficiency because of the UV absorption in the top GaN:Mg layer. ${ }^{3,4}$ Even for blue GaN LEDs, which possess a $\mathrm{p}-\mathrm{GaN}$ contact layer on top of the structure, the high resistance of this layer requires the use of a thin semitransparent conductive electrode (e.g. ITO and Ni/Au) in order to increase current spreading. ${ }^{5-7}$ This solution is well suited for visible LEDs - however, it is barely applicable for other applications such as vertical-cavity surface-emitting lasers (VCSELs) ${ }^{8}$ where intracavity contacts are needed. For both types of emitters, tunnel junctions (TJs) come as a possible solution as both contacts are of " $n$ " nature. In addition, out-of-equilibrium hole generation will increase hole injection in the active region, thus improving the performance of the device..$^{9,10}$

In order to produce efficient tunnel junctions, one has to use very high $\mathrm{n}$ and $\mathrm{p}$-type doping levels, typically higher than $10^{20} \mathrm{~cm}^{-3}$. This, in turns, creates specific problems. For p-doping for instance, the most viable source of acceptors in III-N semiconductors is $\mathrm{Mg}$, but high Mg doping results in defective materials. ${ }^{11-13}$ For n-doping, however, debate has been going on over the past years on which dopant is more effective. Most groups are using Si, which is the traditional source of donors in $\mathrm{GaN}$ and $\mathrm{AlGaN}$ structures, while Ge-doping is increasingly used around the world. Claims in favor of Ge-doping are their similar size to Ga atoms (introducing less stress in the structure than Si at high doping levels, also being compressive instead of tensile, which is the case for the latter), ${ }^{14-16}$ and the shallow behavior of its donors in GaN. ${ }^{17}$ Additionally, it has been shown that, in $\mathrm{NH}_{3}-\mathrm{MBE}, \mathrm{Si}$ is much more susceptible to react with ammonia than $\mathrm{Ge},{ }^{18,19}$ an issue that could limit the Si flux and thus its doping levels due to a nitridation of the Si cell.

Germanium n-doped GaN tunnel junctions on top of visible GaN LEDs were already demonstrated by Neugebauer et $\mathrm{al}^{20}$ using an all-MOCVD growth approach - nonetheless, this growth method is not optimal for tunnel junctions due to the re-passivation of the $\mathrm{Mg}$ acceptors by the $\mathrm{H}$ present in the growth chamber. A post-growth annealing to reactivate these acceptors would 
then be necessary, ${ }^{21}$ but the p-doped layers in TJ devices are always buried under a highly n-doped layer, hindering the diffusion of $\mathrm{H}^{22-24}$ Additionally, for Ge-doped AlGaN layers, the Ge activation energy increases with the concentration of $\mathrm{Al},{ }^{25}$ which yields a new challenge. Nonetheless, high electron concentrations $\left(>1 \times 10^{20} \mathrm{~cm}^{-3}\right)$ can be achieved with Ge-doped $\mathrm{GaN}^{14}$ and $\mathrm{AlGaN}^{25}$ layers by MBE.

The growth of TJ-LEDs was shown to be more effective through a hybrid approach, which involves growing the light-emitting part of the stack by MOCVD (followed by the post-growth annealing) and then changing to an MBE reactor for growing the $n++$ part of the TJs, thus saving the $\mathrm{Mg}$ acceptors in the p-layers from the re-passivation cited above since the MBE growth conditions do not favor the incorporation of $\mathrm{H}$ into the p-layers. ${ }^{23,26}$ The lack of chemical treatment for cleaning the regrown surface was shown to be beneficial to the device, since the creation of midgap states by defects might increase the tunneling probability (by trap-assisted-tunneling). ${ }^{23,27}$ The insertion of an interlayer between the TJ layers would also increase the tunneling probability by profiting from an additional polarization field, which narrows the tunneling width and allows to reach lower resistance tunnel junction devices. ${ }^{28-33}$

In this work, we report on the use of Ge doping for growing the $n++$ part of hybrid MBE/MOCVD GaN and AlGaN tunnel junctions, with and without the insertion of a $\mathrm{GaN}$ interlayer, and its application to the realization of blue and UV light-emitting-diodes. The blue and UV LEDs were chosen in order to show that Ge doping can be used in tunnel junctions based on GaN as well as on AlGaN. In the UV, we chose to work in the UV-B region where important applications exist in the medical domain, such as psoriasis treatment, and in material processing, such as resist curing. 


\section{Experimental}

All the LEDs were grown on top of 2 in. sapphire substrates, with the emitting-structures (i.e. the stacking up to the $\mathrm{p}++$ layer of the tunnel junction) grown in a $7 \mathrm{x} 2$ in. MOCVD reactor with a showerhead geometry (the structures are shown in Figure 1). The precursors of Ga, In, Al, $\mathrm{Mg}, \mathrm{Si}$ and $\mathrm{N}$ were trimethylgallium (TMGa) and triethylgallium (TEGa), trimethylindium (TMIn), trimethylaluminium (TMAl), bis(cyclopentadienyl)magnesium $\left(\mathrm{Cp}_{2} \mathrm{Mg}\right)$, silane $\left(\mathrm{SiH}_{4}\right)$ and ammonia $\left(\mathrm{NH}_{3}\right)$ respectively. For the blue-emitting structures (GaN reference and GaN TJ, shown in Figures 1a and $1 \mathrm{~b}$ respectively), the stacking began with a $1000 \mathrm{~nm}$ non-intentionally doped GaN template, followed by $2000 \mathrm{~nm}$ of Si-doped $\mathrm{GaN}\left([\mathrm{Si}]=6 \times 10^{18} \mathrm{~cm}^{-3}\right)$ and 5 quantum wells [2nm $\left.\mathrm{In}_{0.15} \mathrm{Ga}_{0.85} \mathrm{~N} / 12 \mathrm{~nm} \mathrm{GaN}\right]$. Then, the $\mathrm{Al}_{0.15} \mathrm{Ga}_{0.85} \mathrm{~N}$ electron-blocking-layer (20nm) and the $\mathrm{Mg}$ doped layers (100nm of GaN : Mg with $[\mathrm{Mg}]=3 \times 10^{19} \mathrm{~cm}^{-3}$ and $10 \mathrm{~nm}$ of $\mathrm{GaN}: \mathrm{Mg}$ p++ with $[\mathrm{Mg}]$ $=1 \times 10^{20} \mathrm{~cm}^{-3}$ ) were grown. The LEDs were annealed under $\mathrm{N}_{2}$ atmosphere to activate the $\mathrm{Mg}$ acceptors for $20 \mathrm{~min}$ at $700^{\circ} \mathrm{C}$. The electron concentrations were estimated by Hall Effect measurements.

The UV-emitting structures (the AlGaN reference without TJ, as well as the bottom part to the p++ layer of the AlGaN TJ and AlGaN interlayer TJs, as depicted in Figures 1c, 1d and 1e respectively) were grown in the same MOCVD reactor using the same precursors. The complete MOCVD growth stack consisted of: $1000 \mathrm{~nm}$ AlN buffer; $1000 \mathrm{~nm} n-\mathrm{Al}_{0.5} \mathrm{Ga}_{0.5} \mathrm{~N}\left([\mathrm{Si}]=1 \times 10^{19} \mathrm{~cm}^{-}\right.$ $\left.{ }^{3}\right) ; 3 x\left[\mathrm{Al}_{0.3} \mathrm{GaN}(1.5 \mathrm{~nm}) / \mathrm{Al}_{0.5} \mathrm{Ga}_{0.5} \mathrm{~N}(16 \mathrm{~nm})\right]$ quantum wells; 20nm p- $\mathrm{Al}_{0.7} \mathrm{Ga}_{0.3} \mathrm{~N}$ EBL; 50nm p$\mathrm{Al}_{0.5} \mathrm{Ga}_{0.5} \mathrm{~N}\left([\mathrm{Mg}]=3 \times 10^{19} \mathrm{~cm}^{-3}\right)$ and a $20 \mathrm{~nm} \mathrm{p}++\mathrm{Al}_{0.5} \mathrm{Ga}_{0.5} \mathrm{~N}: \mathrm{Mg}$ cap $\left([\mathrm{Mg}]=1 \times 10^{20} \mathrm{~cm}^{-3}\right)$. These structures went under the same annealing as the blue LEDs for activation of the Mg-acceptors.

Later, the LEDs were taken to a Riber MBE system for the growth of the upper part of the tunnel junctions. The MBE is equipped with $\mathrm{Ga}$ and Ge solid sources, as well as $\mathrm{NH}_{3}$ as a precursor for N. For the blue GaN TJ, the stacking consisted of $20 \mathrm{~nm} \mathrm{n++} \mathrm{GaN}\left([\mathrm{Ge}]=5 \times 10^{20} \mathrm{~cm}^{-3}\right)$ and 200 
$\mathrm{nm} \mathrm{n}+\mathrm{GaN}$ contact layer $\left([\mathrm{Ge}]=1 \times 10^{19} \mathrm{~cm}^{-3}\right)$. For the AlGaN TJ, the MBE growth consisted of $10 \mathrm{~nm} \mathrm{n}++\mathrm{Al}_{0.5} \mathrm{Ga}_{0.5} \mathrm{~N}\left([\mathrm{Ge}]=5 \times 10^{20} \mathrm{~cm}^{-3}\right), 100 \mathrm{~nm} \mathrm{n}+\mathrm{Al}_{0.5} \mathrm{Ga}_{0.5} \mathrm{~N}\left([\mathrm{Ge}]=1 \times 10^{20} \mathrm{~cm}^{-3}\right)$ and $10 \mathrm{~nm}$ $\mathrm{n}++\mathrm{Al}_{0.5} \mathrm{Ga}_{0.5} \mathrm{~N}\left([\mathrm{Ge}]=5 \times 10^{20} \mathrm{~cm}^{-3}\right)$. In the case of the AlGaN interlayer TJ (Figure 1e), a $3.4 \mathrm{~nm}$ GaN interlayer (IL) was grown, followed by $25 \mathrm{~nm} \mathrm{n}++\mathrm{Al}_{0.5} \mathrm{Ga}_{0.5} \mathrm{~N}\left([\mathrm{Ge}]=5 \times 10^{20} \mathrm{~cm}^{-3}\right), 100 \mathrm{~nm} \mathrm{n+}$ $\mathrm{Al}_{0.5} \mathrm{Ga}_{0.5} \mathrm{~N}\left([\mathrm{Ge}]=1 \times 10^{20} \mathrm{~cm}^{-3}\right)$ and $10 \mathrm{~nm} \mathrm{n}++\mathrm{Al}_{0.5} \mathrm{Ga}_{0.5} \mathrm{~N}\left([\mathrm{Ge}]=5 \times 10^{20} \mathrm{~cm}^{-3}\right)$.

The morphology and roughness of the surfaces were evaluated by atomic force microscopy (AFM). For the fabrication of the LEDs, the samples were processed in clean room using standard photolithography and reactive ion etching steps to produce mesas of $0.01 \mathrm{~mm}^{2}$ and $0.0016 \mathrm{~mm}^{2}$ for the GaN and the AlGaN LEDs respectively. The ohmic n contacts of all the LEDs were deposited by e-beam evaporation, consisting of a stack of $\mathrm{Ti} / \mathrm{Al} / \mathrm{Ni} / \mathrm{Au}(30 / 180 / 40 / 200 \mathrm{~nm}$ respectively). It is important to notice that, in the case of the tunnel junctions, both contacts are of $n$ nature. For the $\mathrm{GaN}$ and $\mathrm{AlGaN}$ references (samples without $\mathrm{TJs}$ ), a thin $\mathrm{Ni} / \mathrm{Au}(5 / 5 \mathrm{~nm}$ ) stack (semitransparent electrode) was grown on top of the mesas in order to homogenize current spreading in the p-side, followed by the deposition of $\mathrm{Ni} / \mathrm{Au}(20 / 200 \mathrm{~nm})$ for the $\mathrm{p}$ contacts. The $\mathrm{n}$-contacts and the semitransparent electrode were annealed by rapid thermal annealing under an $\mathrm{N}_{2}$ atmosphere $\left(450^{\circ} \mathrm{C}\right.$ and $750^{\circ} \mathrm{C}$ for the semitransparent electrode and $\mathrm{n}$ contacts respectively).

The electrical and optical characterization were realized on wafer under $\mathrm{CW}$ conditions at room temperature using a Keithley 2104 sourcemeter and a BWTek spectrometer, respectively. The UV emitting samples had their optical characteristics measured using a spectrometer and a calibrated photodiode adapted to UV light. The photodiodes were positioned under the LED to collect the backside emission, i.e. from the sapphire side. 


\section{$\underline{\text { Results and discussion }}$}

Figure 2 shows the AFM images of the samples. It is important to remember that the surfaces of the GaN and $\mathrm{AlGaN}$ References (Figures 2a and 2b) consist of heavily p-doped layers, while for the GaN TJ and AlGaN TJ (Figures 2c and 2d) they are heavily n-doped. This heavy Ge doping in $\mathrm{GaN}$ and $\mathrm{AlGaN}$ contributes to an increase in surface roughness, in this case of $2.5 \mathrm{~nm}$ and $1.9 \mathrm{~nm}$ respectively. Also, we observe the formation of V-pits in the surfaces of both the Gedoped layers related to the decoration of threading dislocations ${ }^{20,34}$. These pits are thicker and deeper for the the GaN TJ (average thickness of 100nm and depth of 30nm) than for the AlGaN TJ (average thickness of $52 \mathrm{~nm}$ and depth of $2 \mathrm{~nm}$ ).

In order to verify the feasibility of highly Ge-doped layers in our lab (i.e. n++ doping higher than $10^{20} \mathrm{~cm}^{-3}$ ) we grew calibration samples of Ge-doped GaN by MBE at a growth rate of $11 \mathrm{~nm} / \mathrm{min}$ under Ge cell temperatures varying from $950^{\circ} \mathrm{C}$ to $1150^{\circ} \mathrm{C}$, and measured the electron concentration by Hall effect (Figure 3). The electron concentration increases following the Ge flux, proportional to the beam equivalent pressure (in Torr) measured in the MBE reactor. At $1150^{\circ} \mathrm{C}$ the electron concentration obtained was $3.5 \times 10^{20} \mathrm{~cm}^{-3}$. We also grew a calibration sample under a lower growth rate of $5.5 \mathrm{~nm} / \mathrm{min}$, being able to obtain an electron concentration of $5.5 \times 10^{20} \mathrm{~cm}^{-3}$, with a mobility of $67 \mathrm{~cm}^{2} /$ V.s and a resistivity of $1.7 \times 10^{-4} \Omega . \mathrm{cm}$ at $1050^{\circ} \mathrm{C}$, achieving state-of-theart mobility and resistivity at this carrier concentration..$^{17,35}$

Room temperature CW electroluminescence measurements performed on the wafers are shown in Figure 4. The peak emission wavelengths are $436 \mathrm{~nm}$ for the blue (Fig. 4a) and 304nm for UV LEDs (Fig. 4b, which shows only AlGaN TJ since both the TJs and the AlGaN reference were grown on the same LED structure and emit at the same wavelength with very similar intensities). The deep-level emission is considerably weaker than the band edge emission for the GaN and AlGaN LEDs respectively.

The current density versus voltage and optical power versus current density graphs are shown in Figures 5a and 5b, respectively, for the GaN reference and TJ. At current densities of 100 
and $500 \mathrm{~A} / \mathrm{cm}^{2}$, the voltages showed by $\mathrm{GaN} \mathrm{TJ}$ are 5.3 and $6.6 \mathrm{~V}$, against 5.6 and $7.0 \mathrm{~V}$ for its reference. We thus observe a slight decrease of the total bias in the TJ-based blue LED, with values which remain however quite large as the overall structure is not optimized.

In terms of optical power (Figure 5b), the difference was also not very significant: 0.9 and $2.9 \mathrm{~mW}$ against 0.7 and $2.3 \mathrm{~mW}$ for the reference, at 100 and $500 \mathrm{~A} / \mathrm{cm}^{2}$ respectively. The slight improvement in optical power between the GaN TJ and its reference is attributed to a better transparency of the TJ based LED since the semitransparent Ni/Au electrode has been suppressed. In the literature, higher voltages were found on Ge-doped $\mathrm{GaN}$ tunnel junctions fully-grown by $\operatorname{MOCVD}\left(8.6 \mathrm{~V} \text { at } 10 \mathrm{~A} / \mathrm{cm}^{2}\right)^{20}$ - however, there is still considerable optimization to be made, since Si-doped hybrid GaN TJs developed by Mughal et al. ${ }^{26}$ exhibited voltages of $3.9 \mathrm{~V}$ at $100 \mathrm{~A} / \mathrm{cm}^{2}$.

The same J-V characteristics are shown in Figure 6a for the AlGaN TJ LEDs and their AlGaN reference. Both AlGaN TJs exhibit a higher operating voltage than the AlGaN Reference. The interlayer present inside the TJs have a strong impact on the electrical behavior of the LED. For a current density of $1000 \mathrm{~A} / \mathrm{cm}^{2}$, the total voltage drops from the AlGaN TJ to the IL TJ. Compared to their reference, the voltage penalty varies from $4.6 \mathrm{~V}$ to $2 \mathrm{~V}$ respectively, proving the positive effect of the GaN interlayer in the electrical behavior of the LEDs, as expected. There remains room for improvement - replacing the GaN interlayer by an $\mathrm{InGaN}$ one should lead to larger tunnel currents due to a larger band bending across the space charge region thus decreasing the barrier width and increasing the tunneling probability. ${ }^{29}$ The differential resistance at $1000 \mathrm{~A} / \mathrm{cm}^{2}$ achieved by the AlGaN IL TJ was $1.2 \times 10^{-3} \Omega \mathrm{cm}^{2}$, while the TJ without interlayer led to a value of $1.7 \times 10^{-3} \Omega \mathrm{cm}^{2}$. The electrical behavior of these LEDs is placed between the results obtained by both Kuhn et al ${ }^{31}$ (voltages around $20 \mathrm{~V}$ at $20 \mathrm{~mA}$ and resistances of 4-6 $\times 10^{-3} \Omega \mathrm{cm}^{2}$ at $350 \mathrm{~A} / \mathrm{cm}^{2}$ for a $268 \mathrm{~nm}$-emission structure) and Zhang et $\mathrm{al}^{36}$ (voltages of $18 \mathrm{~V}$ around $1000 \mathrm{~A} / \mathrm{cm}^{2}$ for a $257 \mathrm{~nm}$-emission structure), and those obtained by Zhang et al ${ }^{10}$ (voltages of $6 \mathrm{~V}$ at $1000 \mathrm{~A} / \mathrm{cm}^{2}$ 
and resistances of $1 \times 10^{-3} \Omega \mathrm{cm}^{2}$ ) for a $327 \mathrm{~nm}$-emission structure. This result is consistent with the expectations of a decreasing performance as the wavelength of emission decreases. ${ }^{1,37}$

Figure $6 \mathrm{~b}$ shows the optical power versus the current density of the UV LEDs. The optical powers at $1000 \mathrm{~A} / \mathrm{cm}^{2}$ are $1.9 \mu \mathrm{W}$ for the $\mathrm{AlGaN}$ reference and $5.3 \mu \mathrm{W}$ and $12 \mu \mathrm{W}$ for the $\mathrm{AlGaN}$ $\mathrm{TJ}$ and $\mathrm{AlGaN}$ IL TJ respectively. These values are low compared to the current state of the art due to the high dislocation density in the AlN buffer layer $\left(>10^{10} \mathrm{~cm}^{-2}\right)$ which decreases the internal quantum efficiency of the AlGaN/AlGaN QWs. However, it allows a clear comparison between the samples. In particular, both the TJ based LEDs have an output power which is increased, compared to the AlGaN reference, by a factor of 3 for the AlGaN TJ and 6 for the AlGaN IL TJ. Let us recall that the external quantum efficiency (EQE) is the product of the internal quantum efficiency (IQE), by the electrical injection efficiency (EIE) and by the light extraction efficiency (LEE). The IQE is not expected to depend on the presence of the TJ. The LEE may be improved in the TJ based LEDs by the difference in the contact metals used - however, the results obtained on the blue LEDs show that this effect remains limited in our case. Hence, our results seem to indicate that the electrical injection efficiency is largely improved by the presence of the TJ. As the TJ injects out of equilibrium holes into the LED, the balance between electrons and holes in the quantum wells is improved, which enhances the injection efficiency. In other words, while electrons tend to overflow above the QW in the standard UV LED due to the lack of holes and recombine in the p region, electrons recombine in the quantum wells with holes injected from the TJ in TJ based UV LEDs. Such a beneficial effect had not been clearly observed so far, and will come as an important bonus for TJ-LEDs in the UV range in addition to the decrease in access resistances (which is not observed in our case here).

\section{$\underline{\text { Conclusion }}$}

We have synthesized Ge-doped $\mathrm{GaN}$ and $\mathrm{Al}_{0.5} \mathrm{Ga}_{0.5} \mathrm{~N}$ tunnel junctions on top of blue $\mathrm{GaN}$ and $\mathrm{UV} \mathrm{Al}_{0.5} \mathrm{Ga}_{0.5} \mathrm{~N}$ light emitters, respectively. For the latter case, a sample with a $\mathrm{GaN}$ interlayer 
was also grown. Hall effect measurements at room temperature show state of the art mobility $\left(67 \mathrm{~cm}^{2} / \mathrm{V} . \mathrm{s}\right)$ and resistivity $\left(1.7 \times 10^{-4} \Omega . \mathrm{cm}\right)$ at an electron concentration of $5.5 \times 10^{20} \mathrm{~cm}^{-3}$ for Gedoped GaN. While such a high concentration is beneficial for the tunnel transparency, it degrades the layer morphology by creating V-pits and increasing the roughness of the surface. Room temperature $\mathrm{CW}$ electroluminescence measurements on wafer showed single peak emission wavelengths of $436 \mathrm{~nm}$ for the blue and 304nm for the UV LEDs, with weak deep-level emission in comparison with the band edge emission in both cases. The GaN TJ slightly increased the LED optical power, due to a better transparency of the upper contact layer of the device. For the UV emitters, the TJs caused voltage drops in the devices, but this was significantly reduced by the use of a GaN interlayer in the tunnel junction. The AlGaN TJs increased the optical power of the UV LEDs, obtaining significant improvements (up to a factor of 6 for the AlGaN interlayer TJ), and thus indicating higher electrical injection efficiencies by the use of tunnel junctions in UV emitting structures.

\section{$\underline{\text { Acknowledgements }}$}

We would like to thank GaNeX (ANR-11-LABX-0014) and the French National Research Agency (ANR) for funding this research through the DUVET project (ANR-17-CE080024), and Drs. Jean Massies, Julien Brault and Mathieu Leroux for the critical reading of this paper. 


\section{$\underline{\text { References }}$}

${ }^{1}$ J. Verma, P.K. Kandaswamy, V. Protasenko, A. Verma, H. Grace Xing, and D. Jena, Appl. Phys. Lett. 102, 041103 (2013).

${ }^{2}$ C. De Santi, M. Meneghini, D. Monti, J. Glaab, M. Guttmann, J. Rass, S. Einfeldt, F. Mehnke, J. Enslin, T. Wernicke, M. Kneissl, G. Meneghesso, and E. Zanoni, Photonics Res. 5, A44 (2017).

${ }^{3}$ M. Shatalov, W. Sun, R. Jain, A. Lunev, X. Hu, A. Dobrinsky, Y. Bilenko, J. Yang, G.A. Garrett, L.E. Rodak, M. Wraback, M. Shur, and R. Gaska, Semicond. Sci. Technol. 29, 084007 (2014).

${ }^{4}$ H. Hirayama, N. Maeda, S. Fujikawa, S. Toyoda, and N. Kamata, Jpn. J. Appl. Phys. 53, 100209 (2014).

${ }^{5}$ M.R. Krames, O.B. Shchekin, R. Mueller-Mach, G.O. Mueller, L. Zhou, G. Harbers, and M.G. Craford, J. Disp. Technol. 3, 160 (2007).

${ }^{6}$ V. Fan Arcara, B. Damilano, G. Feuillet, A. Courville, S. Chenot, and J.-Y. Duboz, AIP Adv. 9, 055101 (2019).

${ }^{7}$ J.H. Kim, G. Kim, E. Park, D.H. Kang, and B.-G. Park, J. Semicond. Technol. Sci. 15, 115 (2015).

${ }^{8}$ D. Kasahara, D. Morita, T. Kosugi, K. Nakagawa, J. Kawamata, Y. Higuchi, H. Matsumura, and T. Mukai, Appl. Phys. Express 4, 072103 (2011).

${ }^{9}$ Y. Zhang, S. Krishnamoorthy, F. Akyol, A.A. Allerman, M.W. Moseley, A.M. Armstrong, and S. Rajan, Appl. Phys. Lett. 109, 191105 (2016).

${ }^{10}$ Y. Zhang, S. Krishnamoorthy, J.M. Johnson, F. Akyol, A. Allerman, M.W. Moseley, A. Armstrong, J. Hwang, and S. Rajan, Appl. Phys. Lett. 106, 141103 (2015).

${ }^{11}$ P. Vennéguès, M. Leroux, S. Dalmasso, M. Benaissa, P. De Mierry, P. Lorenzini, B. Damilano, B. Beaumont, J. Massies, and P. Gibart, Phys. Rev. B 68, 235214 (2003).

${ }^{12}$ P. Vennéguès, M. Benaissa, B. Beaumont, E. Feltin, P. De Mierry, S. Dalmasso, M. Leroux, and P. Gibart, Appl. Phys. Lett. 77, 880 (2000).

${ }^{13}$ M. Leroux, P. Vennegues, S. Dalmasso, M. Benaissa, E. Feltin, P. de Mierry, B. Beaumont, B. Damilano, N. Grandjean, and P. Gibart, 7 (2002).

${ }^{14}$ M.N. Fireman, G. L'Heureux, F. Wu, T. Mates, E.C. Young, and J.S. Speck, J. Cryst. Growth 508, 19 (2019).

${ }^{15}$ S. Fritze, A. Dadgar, H. Witte, M. Bügler, A. Rohrbeck, J. Bläsing, A. Hoffmann, and A. Krost, Appl. Phys. Lett. 100, 122104 (2012).

${ }^{16}$ A. Cremades, L. Görgens, O. Ambacher, M. Stutzmann, and F. Scholz, Phys. Rev. B 61, 2812 (2000).

${ }^{17}$ A. Ajay, J. Schörmann, M. Jiménez-Rodriguez, C.B. Lim, F. Walther, M. Rohnke, I. Mouton, L. Amichi, C. Bougerol, M.I. Den Hertog, M. Eickhoff, and E. Monroy, J. Phys. Appl. Phys. 49, 445301 (2016).

${ }^{18}$ D. Aubel, J. Vac. Sci. Technol. B Microelectron. Nanometer Struct. 12, 2699 (1994).

${ }^{19}$ M. Mukhopadhyay, J. Vac. Sci. Technol. B Microelectron. Nanometer Struct. 14, 1682 (1996).

${ }^{20}$ S. Neugebauer, M.P. Hoffmann, H. Witte, J. Bläsing, A. Dadgar, A. Strittmatter, T. Niermann, M. Narodovitch, and M. Lehmann, Appl. Phys. Lett. 110, 102104 (2017).

${ }^{21}$ S. Nakamura, T. Mukai, M. Senoh, and N. Iwasa, Jpn. J. Appl. Phys. 31, L139 (1992).

${ }^{22}$ D. Hwang, A.J. Mughal, M.S. Wong, A.I. Alhassan, S. Nakamura, and S.P. DenBaars, Appl. Phys. Express 11, 012102 (2018).

${ }^{23}$ E.C. Young, B.P. Yonkee, F. Wu, S.H. Oh, S.P. DenBaars, S. Nakamura, and J.S. Speck, Appl. Phys. Express 9, 022102 (2016).

${ }^{24}$ Y. Kuwano, M. Kaga, T. Morita, K. Yamashita, K. Yagi, M. Iwaya, T. Takeuchi, S. Kamiyama, and I. Akasaki, Jpn. J. Appl. Phys. 52, 08JK12 (2013).

${ }^{25}$ R. Blasco, A. Ajay, E. Robin, C. Bougerol, K. Lorentz, L.C. Alves, I. Mouton, L. Amichi, A. Grenier, and E. Monroy, J. Phys. Appl. Phys. 52, 125101 (2019). 
${ }^{26}$ A.J. Mughal, E.C. Young, A.I. Alhassan, J. Back, S. Nakamura, J.S. Speck, and S.P. DenBaars, Appl. Phys. Express 10, 121006 (2017).

${ }^{27}$ E. Vadiee, E.A. Clinton, H. McFavilen, A.S. Weidenbach, Z. Engel, C. Matthews, C. Zhang, C. Arena, R.R. King, C.B. Honsberg, and W.A. Doolittle, Appl. Phys. Express 11, 082304 (2018).

${ }^{28}$ S. Krishnamoorthy, F. Akyol, P.S. Park, and S. Rajan, Appl. Phys. Lett. 102, 113503 (2013).

${ }^{29}$ S. Krishnamoorthy, D.N. Nath, F. Akyol, P.S. Park, M. Esposto, and S. Rajan, Appl. Phys. Lett. 97, 203502 (2010).

${ }^{30}$ F. Akyol, Y. Zhang, S. Krishnamoorthy, and S. Rajan, Appl. Phys. Express 10, (2017).

${ }^{31}$ C. Kuhn, L. Sulmoni, M. Guttmann, J. Glaab, N. Susilo, T. Wernicke, M. Weyers, and M. Kneissl, Photonics Res. 7, B7 (2019).

${ }^{32}$ Z.-H. Zhang, S. Tiam Tan, Z. Kyaw, Y. Ji, W. Liu, Z. Ju, N. Hasanov, X. Wei Sun, and H. Volkan Demir, Appl. Phys. Lett. 102, 193508 (2013).

${ }_{33}^{33}$ J.-Y. Duboz and B. Vinter, J. Appl. Phys. 126, 174501 (2019).

${ }^{34}$ O.N. Carlson, Bull. Alloy Phase Diagr. 11, 567 (1990).

${ }^{35}$ L. Lugani, M. Malinverni, S. Tirelli, D. Marti, E. Giraud, J.-F. Carlin, C.R. Bolognesi, and N. Grandjean, Appl. Phys. Lett. 105, 202113 (2014).

${ }^{36}$ Y. Zhang, S. Krishnamoorthy, F. Akyol, S. Bajaj, A.A. Allerman, M.W. Moseley, A.M. Armstrong, and S. Rajan, Appl. Phys. Lett. 110, 201102 (2017).

${ }^{37}$ Y. Zhang, S. Krishnamoorthy, F. Akyol, A.A. Allerman, M.W. Moseley, A.M. Armstrong, and S. Rajan, Appl. Phys. Lett. 109, 121102 (2016). 


\section{Figure captions}

Figure 1. Structures of the samples. a) GaN reference (without TJ); b) GaN TJ;) c) AlGaN reference (without TJ); d) AlGaN TJ; e) AlGaN IL TJ

Figure 2. 10x10 $\mathrm{\mu m} 2$ atomic force microscopy images of (a) GaN reference, (b) AlGaN reference, (c) GaN TJ and (d) AlGaN TJ.

Figure 3. Hall effect measurements of free electron concentration and beam equivalent pressure versus Ge cell temperature for Ge-doped GaN epilayers grown by MBE.

Figure 4. Room temperature electroluminescence measurements of (a) GaN TJ; (b) AlGaN TJ.

Figure 5. Current density versus bias (a) and optical power versus current density (b) for the GaN TJ and its GaN reference without TJ. The LEDs had an area of $0.01 \mathrm{~mm}^{2}$.

Figure 6. Current density versus bias (a) and optical power (b) for the AlGaN TJs and their AlGaN reference without TJ. The LEDs had an area of $0.0016 \mathrm{~mm}^{2}$. 
GaN Reference

p++ GaN : Mg 10 nm

GaN : Mg 100 nm

AlGaN $20 \mathrm{~nm}$

5 [InGaN $(2 \mathrm{~nm}) / /$ GaN

$(12 \mathrm{~nm})] \mathrm{QWs}$

GaN : Si 2000 nm

GaN Stnid 1000 nm

a)

Sapphire

GaN TJ

n+ GaN : Ge 200 nm

n++ GaN : Ge 20 nm

b) GaN Reference
AlGaN Reference p++ AlGaN : Mg 20 nm p AlGaN : $M g 50 \mathrm{~nm}$ p $\mathrm{Al}_{0.7} \mathrm{GaN}: \mathrm{Mg} 20 \mathrm{~nm}$ $3 \mathrm{Al}_{0.3} \mathrm{GaN}(1.5 \mathrm{~nm}) / /$ AlGaN (16 nm) QWs AIGaN : Si $1000 \mathrm{~nm}$

c) AIN $1000 \mathrm{~nm}$ Sapphire
AlGaN TJ

n++ AlGaN : Ge 10 nm

n+ AlGaN : Ge 100 nm

n++ AlGaN : Ge 10 nm

d)

AlGaN Reference

\section{AlGaN IL TJ}

n++ AlGaN : Ge 10 nm

n+ AlGaN : Ge 100 nm

n++ AlGaN : Ge 25 nm

GaN interlaver $3.4 \mathrm{~nm}$

e)

AIGaN Reference

Figure 1. Structures of the samples. a) GaN reference (without TJ); b) GaN TJ;) c) AlGaN reference (without TJ); d) AlGaN TJ; e) AlGaN IL TJ 

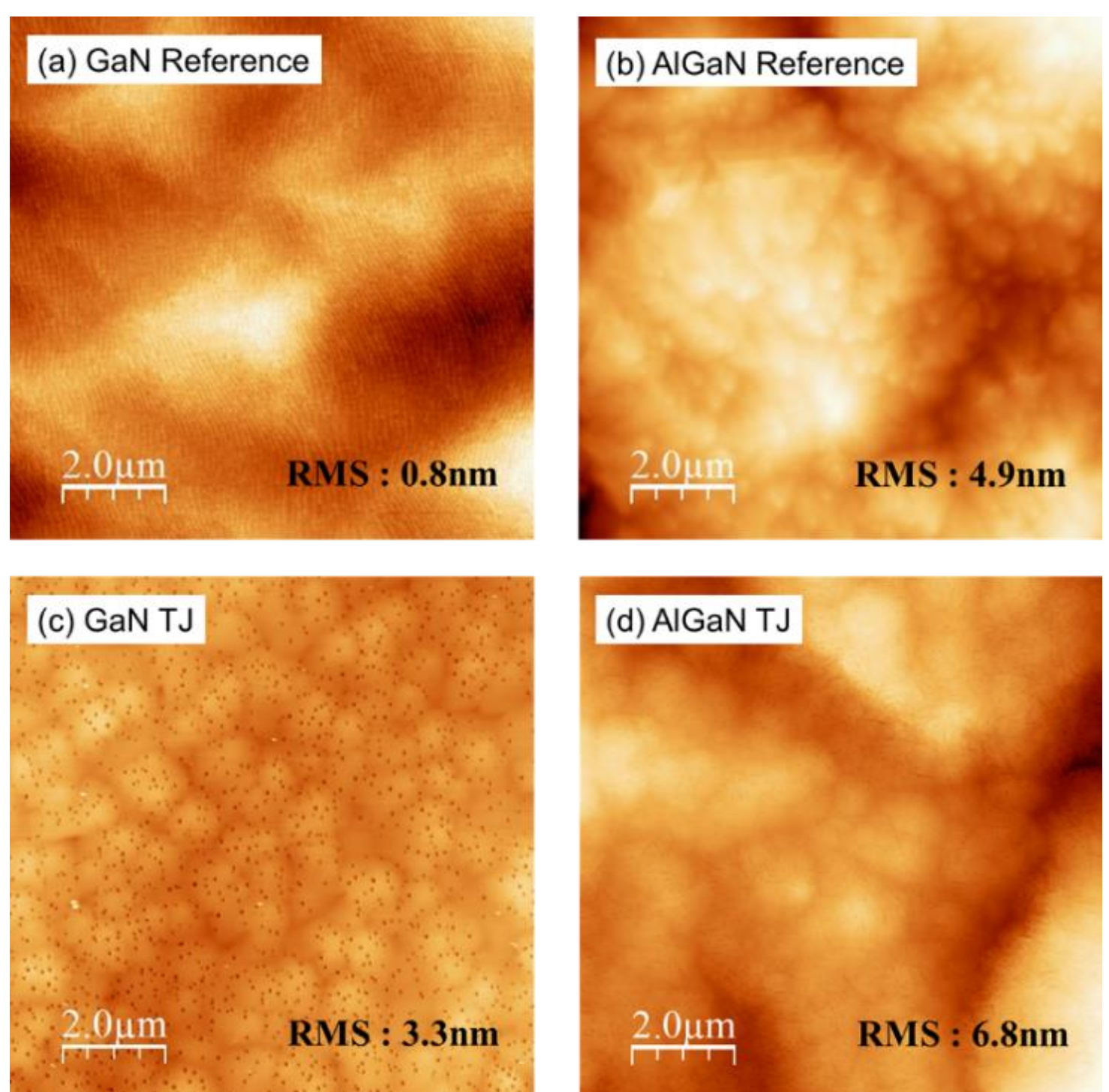

Figure 2. 10x10 $\mu \mathrm{m} 2$ atomic force microscopy images of (a) GaN reference, (b) AlGaN reference, (c) GaN TJ and (d) AlGaN TJ. 


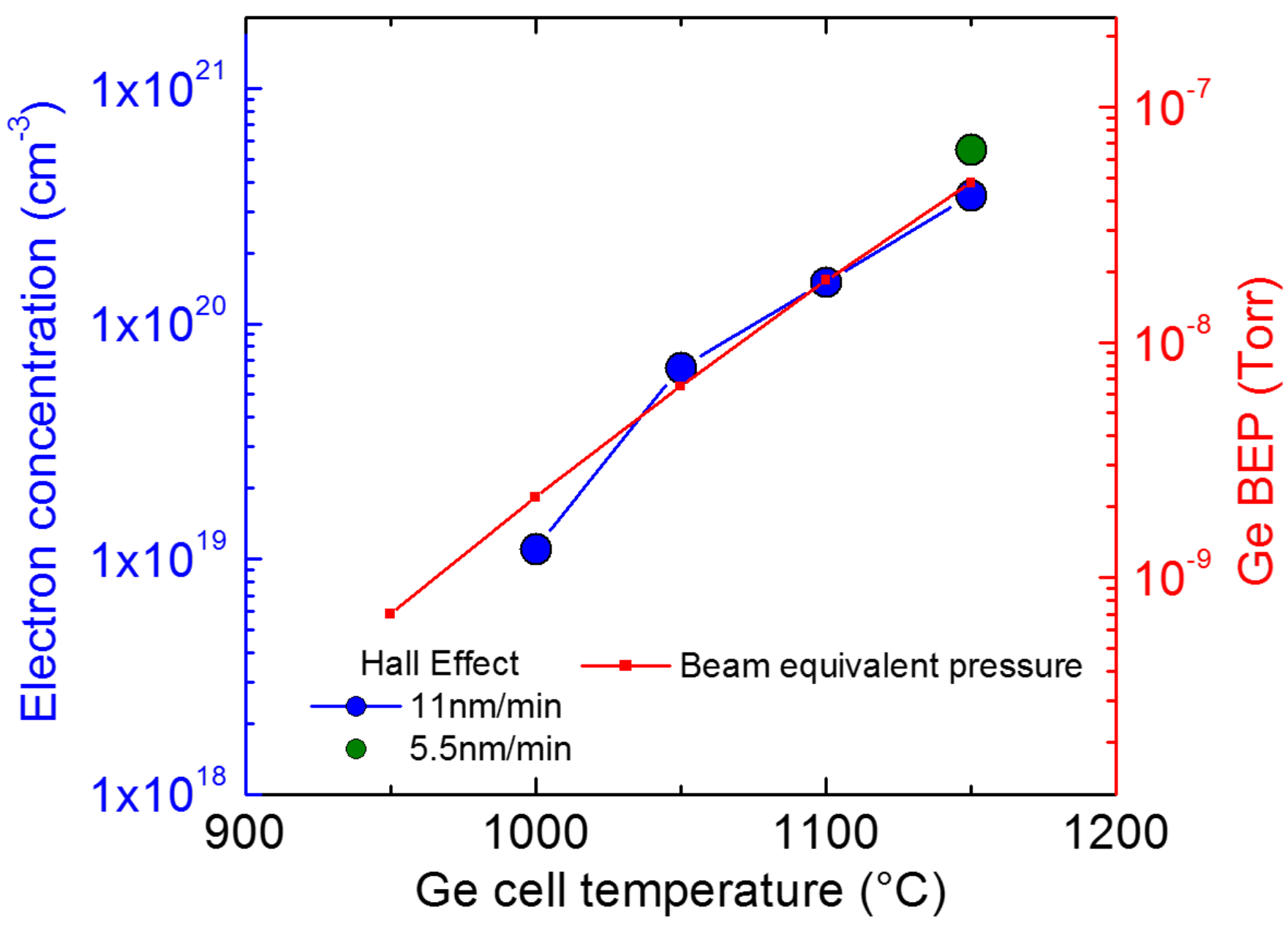

Figure 3. Hall effect measurements of free electron concentration and beam equivalent pressure versus Ge cell temperature for Ge-doped $\mathrm{GaN}$ epilayers grown by MBE. 

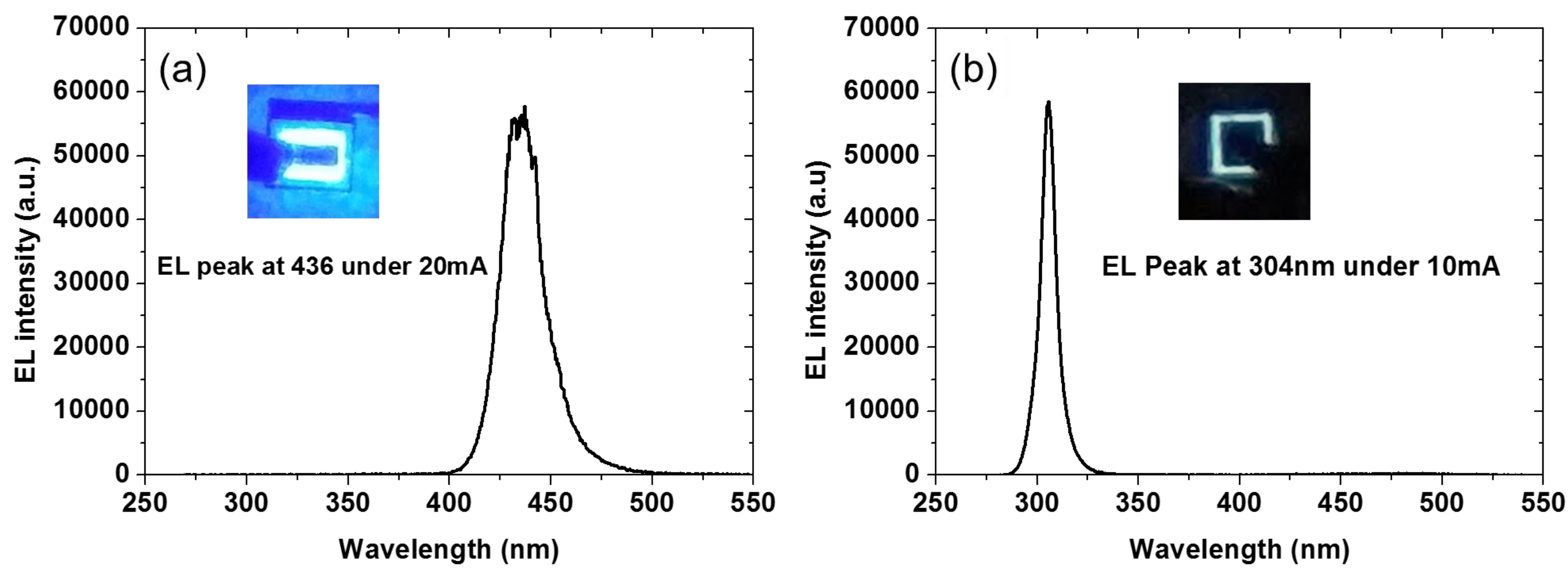

Figure 4. Room temperature electroluminescence measurements of (a) GaN TJ; (b) AlGaN TJ. 

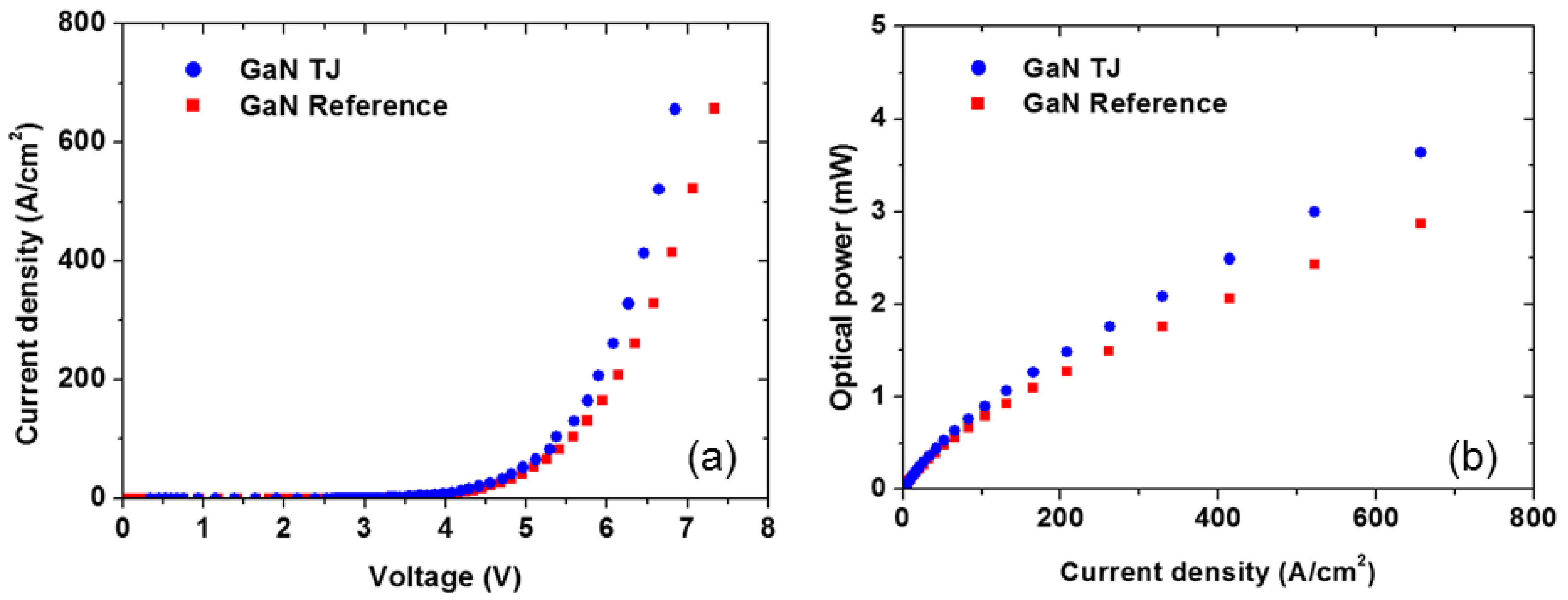

Figure 5. Current density versus bias (a) and optical power versus current density (b) for the GaN TJ and its GaN reference without TJ. The LEDs had an area of $0.01 \mathrm{~mm}^{2}$. 

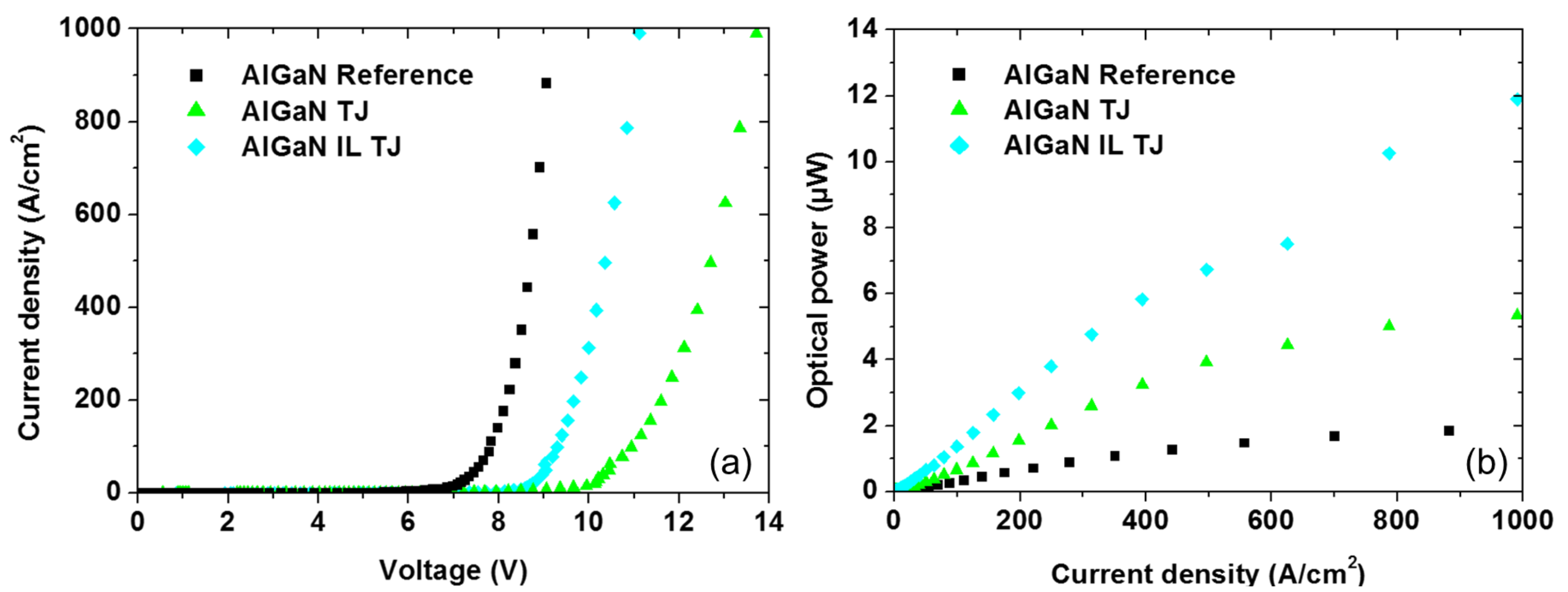

Figure 6. Current density versus bias (a) and optical power (b) for the AlGaN TJs and their AlGaN reference without TJ. The LEDs had an area of $0.0016 \mathrm{~mm}^{2}$. 